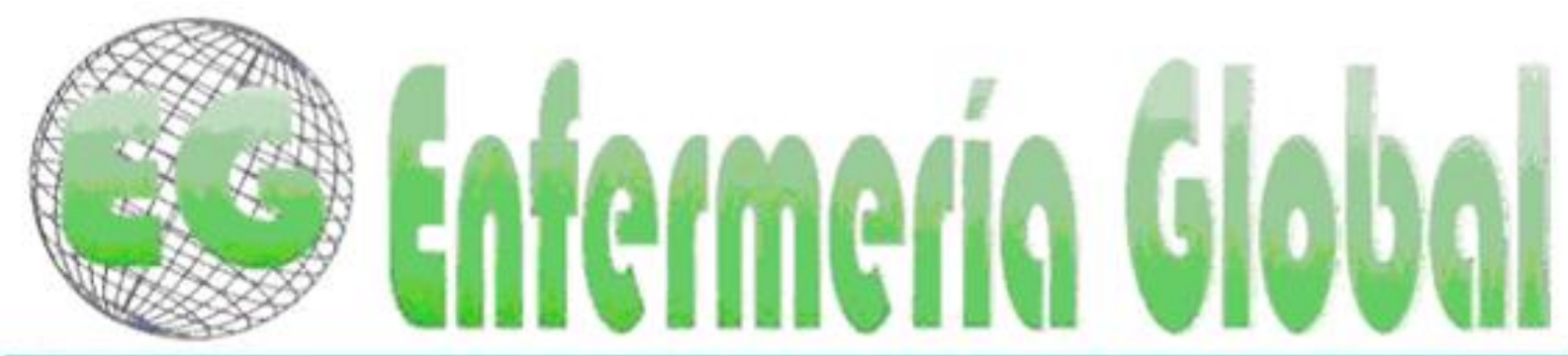

\title{
Enfermedades profesionales de los trabajadores de limpieza en los hospitales: propuesta educativa para minimizar la exposición
}

Doenças ocupacionais dos trabalhadores de limpeza em ambiente hospitalar: proposta educativa para minimizar a exposição

Occupational diseases of workers cleaning service in hospital environment: educational proposal to minimize exposure

\section{*Souza, Raulene de Souza ${ }^{* *}$ Cortez, Elaine Antunes ${ }^{* * *}$ do Carmo, Thalita Gomes ***'Santana, Rosimere Ferreira}

*Enfermera. Posgraduanda en Enfermería del Trabajo de la UFF. ${ }^{* *}$ Doctora en Enfermería (UFRJ). Profesora Adjunta del Departamento materno-infantil y psiquiátrico (MEP) de la Universidad Federal Fluminense (UFF),. Niterói, ${ }^{* * *}$ Máster en Enfermería (UFF). Profesora Asistente de la Universidad Federal de Rio de Janeiro (UFRJ) - Campus Macaé, do Núcleo Clínica Médica-Cirúrgica. Macaé. E-mail: thalitado@gmail.com ****PhD, RN Professora Adjunta, EEAAC/UFF, Niteroi-RJ, Brasil

Palabras clave: Enfermedades profesionales; Servicio de limpieza del Hospital; ambiente de trabajo; trabajador

Palavras chave: Doenças ocupacionais; Serviço hospitalar de limpeza; Ambiente de trabalho; Trabalhador

Keywords: Occupational Diseases; Hospital cleaning service; working environment; Worker.

\section{RESUMEN}

Objetivos: Identificar la enfermedad profesional de los trabajadores de limpieza del hospital; describir los factores causales de las enfermedades profesionales en este grupo de trabajadores, y ofrecer actividades educativas para minimizar la exposición a las enfermedades profesionales en este grupo.

Métodos: Se trata de una revisión integral de la literatura de los últimos cinco años realizada en las bases de datos Lilacs, Medline y BDEnf. Se seleccionaron ocho artículos y después de la lectura y el análisis surgieron tres categorías: (1) las enfermedades profesionales, (2) los factores causales de las enfermedades profesionales, (3) Medidas educativas para minimizar la exposición

Resultados:. Los trabajadores del Servicio de limpieza en sus actividades de trabajo están expuestos a todos los riesgos laborales. Las enfermedades profesionales identificadas en estos trabajadores son diversas, pero llaman la atención: los trastornos musculoesqueléticos y dermatitis. Las medidas 
educativas deben centrarse en la formación / educación continua.

Conclusión: Se concluye que la educación continua puede ser una alternativa para minimizar los diversos riesgos laborales a que estos trabajadores están expuestos, ya que las actividades con un enfoque en la capacitación no son muy eficaces.

\section{RESUMO}

Objetivos: Identificar as doenças ocupacionais entre os trabalhadores de limpeza hospitalar; descrever os fatores causais das doenças ocupacionais neste grupo de trabalhadores; e propor atividades educativas para minimizar a exposição às doenças ocupacionais neste grupo.

Métodos: Trata-se de uma revisão integrativa de literatura dos últimos 5 anos realizada nas bases de dados Lilacs, Bdenf e Medline. Resultados: Oito artigos foram selecionados e após leitura e análise surgiram 3 categorias: (1) Doenças ocupacionais, (2) Fatores causais das doenças ocupacionais, (3) Medidas educativas para minimizar a exposição.

Resultados: O trabalhador do serviço de limpeza na sua atividade laboral está exposto a todos os riscos ocupacionais. As doenças ocupacionais identificadas desses trabalhadores são diversas, mas, destaca-se: distúrbios osteomusculares e dermatites. As medidas educativas tem o foco no treinamento/educação continuada.

Conclusão: Conclui-se que, a educação permanente pode ser uma alternativa para minimizar os diversos riscos ocupacionais que estes trabalhadores estão expostos, já que as atividades com foco no treinamento não estão sendo muito eficazes.

\section{ABSTRACT}

Objectives: To identify the occupational disease among hospital cleaning workers; describe the causal factors of occupational diseases in this group of workers; and offer educational activities to minimize exposure to occupational diseases in this group.

Methods: This is a literature integrative review of the last five years held in databases Lilacs, BDEnf and Medline. Eight articles were selected and after reading and analyzing emerged three categories: (1) Occupational diseases, (2) causal factors of occupational diseases, (3) educational measures to minimize exposure.

Results: Worker cleaning service in their work activities are exposed to all occupational risks. Occupational diseases identified these workers are diverse, but stands out: musculoskeletal disorders and dermatitis. The educational measures must focus on training / continuing education.

Conclusion: We conclude that continuing education can be an alternative to minimize the various occupational hazards that these workers are exposed, since activities with a focus on training are not very effective

\section{INTRODUCCIÓN}

El trabajo surgió con el primer ser humano. La bibliografía hace referencias sobre factores nocivos para el trabajador desde la edad media, con todo, las relaciones entre las actividades laborales y la enfermedad permanecieron prácticamente ignoradas hasta 250 años atrás ${ }^{(1)}$.

En Brasil, solamente en la década de los 40, comenzaron a ser estudiados los problemas causados por el trabajo. La consolidación de las leyes laborales (CLT), la aparición de la Organización Mundial de la Salud (OMS), y la creación del FGTS (Fondo de Garantía por Tiempo de Servicio), INAMPS (Instituto de Previsión Social), hoy INSS (Instituto Nacional de Seguro Social) la Organización internacional del Trabajo, (OIT) y la FUNDACENTRO, fueron marcos en la conquista y mantenimiento de la salud del trabajador ${ }^{(2)}$. 
A pesar de las crecientes modificaciones introducidas en el trabajo, a través de nuevas tecnologías, de cambio en la organización del trabajo y en la aparición de nuevas profesiones, se constata que algunas cuestiones continúan siendo un desafío, tales como el sufrimiento, las enfermedades, los accidentes relacionados con el trabajo. Estas cuestiones, además de tener consecuencias para las personas, acarrean daño para las instituciones y para la sociedad.

La enfermedad laboral o profesional es una enfermedad que el trabajador adquiere debido a la exposición a factores que pueden ser químicos, físicos y biológicos, y que agreden el organismo del trabajador continua o frecuentemente, y por un largo tiempo, en su ambiente de trabajo(3).

Cuando las condiciones de trabajo sobrepasan los limites tolerables del organismo, la probabilidad de provocar una enfermedad en el trabajo es significativa. En este contexto, se encuentran diversos trabajadores, pero este estudio tendrá como foco los trabajadores del servicio de limpieza que trabajan en área hospitalaria. Estos trabajadores al desarrollar sus actividades están expuestos a numerosos riesgos: físicos (temperatura excesiva, humedad, desgaste físico), químicos (contacto con producto de limpieza y desinfección, desecho de quimioterápicos) ergonómicos (esfuerzo físico excesivo, repetitividad de movimentos, postura inadecuada, puesto de trabajo incorrecto), ergonómico cognitivo (desvalorización social del trabajo, pérdida de la motivación), biológico (contacto con material perfuro-cortante durante el transporte para desecho de la caja), que favorecen la aparición de ciertas enfermedades: LER/DORT, dermatitis de contacto, lumbalgias, enfermedades infectocontagiosas $^{(4)}$.

El ritmo de trabajo impuesto a esta clase de trabajadores ha generado condiciones para el desarrollo de numeroas enfermedades ocupacionales destacando entre ellas, la manifestación de las lesiones por esfuerzos repetitivos (LER) o los problemas osteomusculares relacionados con el trabajo (DORT) directamente vinculados a ejecución de actividad repetitiva e incómoda, las LER/DORT encuentran un campo fértil en el ramo de la limpieza, considerando que esta actividad se caracteriza por una demanda laboral dinámica e intensiva, exigiendo movimientos manuales repetitivos e incómodos para el trabajador. Ante lo expuesto, se justifica la necesidad de más estudios sobre los trabajadores de higiene y limpieza hospitalaria, una clase muchas veces olvidada en el ambiente hospitalario y que interactúa directa o indirectamente con el paciente y con los profesionales de salud.

Al aclarar los factores causales que ocasionan estos riesgos, se consigue explorar el problema de forma integrada en el intento de planear y adoptar medidas educativas importantes para prevenir y minimizar su ocurrencia junto a estos trabajadores. De este modo, se pretende contribuir a la prevención de las enfermedades laborales en estos trabajadores y, consecuentemente, contribuir al mantenimiento de su salud.

Para ello este artículo tiene como objetivos: 1) Identificar las enfermedades laborales entre los trabajadores de limpieza hospitalaria; 2) Describir los factores causales de las enfermedades laborales en este grupo de trabajadores; y 3) Proporcionar actividades educativas para minimizar la exposición a las enfermedades laborales entre estos trabajadores. 


\section{METODOLOGÍA}

Se trata de una revisión integral realizada en las siguientes bases: LILACS (Literatura Latino Americana e do Caribe em Ciências e Saúde), Medline (Sistema Online de Busca e Análise de Literatura Médica) y BDENF (Base de Dados em Enfermagem), realizada en el periodo de agosto a diciembre de 2013.

La Revisión integral es un método de revisión más amplio, pues permite incluir literatura teórica y empírica, así como estudios con diferentes enfoques metodológicos (cuantitativo y cualitativo). Este método tiene como principal finalidad reunir y sintetizar los estudios realizados sobre un determinado asunto, construyendo una conclusión, a partir de los resultados evidenciados en cada estudio, pero que investigan problemas idénticos o similares ${ }^{(5)}$.

La revisión integral se divide en seis etapas, siendo la primera identificar el tema y elaboración de la pregunta guía: ¿Cómo proponer medidas educativas a los trabajadores del servicio de limpieza en el ambiente hospitalario, teniendo como foco los factores causales de las enfermedades laborales?

La segunda etapa fue el establecimiento de criterios de inclusión, que fueron: estudios publicados en los últimos cinco años; textos en portugués, artículos científicos que conceptuen los factores causales de las enfermedades laborales en los trabajadores del servicio de limpieza en ambiente hospitalario y medidas para minimizar la exposición. Es criterio de exclusión: trabajos científicos que no atiendan la pregunta del estudio.

En esta etapa se realizó la busca de muestreo en la lectura y establecimiento de los descriptores a ser utilizados, que en esta investigación fueron: trabajadores de limpieza, ambiente hospitalario, enfermedades laborales. Para la busca se utilizó la estrategia PICO, por eso en esta investigación como no hubo comparación se utilizó el PIO, donde el P - (paciente/problema), I - (intervención), O - (resultado/desenlace). La estrategia PICO representa un acrónimo para Paciente, Intervención, Comparación y "Outcomes"(desenlace). Dentro de la PBE (Práctica Basada en Evidencias) estos cuatro componentes son los elementos fundamentales de la pregunta de la investigación y de la construcción de la pregunta para busca bibliográfica de evidencias $^{(6)}$. En esta investigación se utilizó para P - Servicio hospitalario de limpieza - Ambiente de trabajo - Enfermedades Laborales, para I - Factores causales, prevención, y para O - Riesgo de agentes: físicos, químicos, biológicos, ergonómicos.

Se destaca que el nivel de evidencias es aquel que es claro, constatación de una verdad que no suscita ninguna duda. Evidencia científica representa una prueba de que un determinado conocimiento es verdadero o falso ${ }^{(7)}$. En esta investigación será utilizado el nivel de evidencia de acuerdo con la McMaster University (Ontario, Canadá) y de la University of York (Reino Unido) ${ }^{(8)}$, donde se originó la PBE (Práctica Basada en Evidencias, que prevê métodos y procesos para identificación de evidencias).

La tercera etapa consistió en la selección de los trabajos científicos de acuerdo con su concepto basado en fundamentos, objetivo, metodología, definición de las informaciones a ser extraídas de los artículos científicos seleccionados y categorización de los mismos. El camino recorrido para busca y selección de material 
en esta revisión integral se presenta en el Flujograma 1.

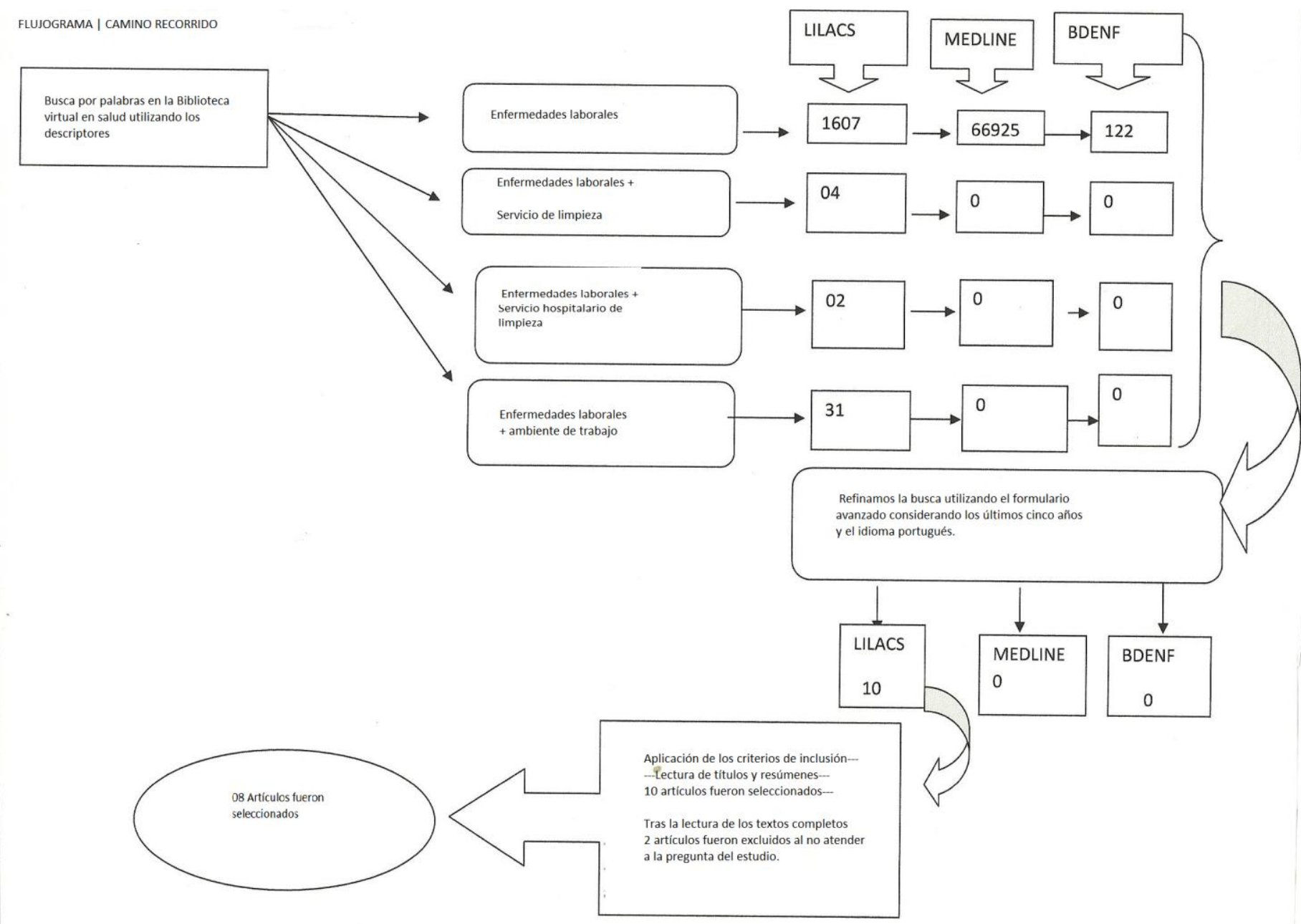

Como cuarta etapa, realizamos la evaluación de los estudios incluidos en la revisión integral y análisis crítico, correlacionándolos.

En la quinta etapa se realizó la interpretación y discusión de los resultados, destacándose los trabajos que trajeron de forma más clara y concisa las diferencias conceptuales entre las vertientes de los factores causales de las enfermedades laborales que fueron investigadas.

Y como sexta y última etapa, fue presentada la revisión y síntesis del conocimiento producido acerca de los factores causales de las enfermedades laborales y las medidas educativas de prevención de las mismas.

Así, emergieron tres ejes temáticos: (1) Enfermedades laborales; (2) Factores causales de las enfermedades laborales; y (3) Medidas educativas para minimizar la exposición. 


\section{RESULTADOS}

A continuación sigue el cuadro sinóptico 1 de las ocho (8) referencias encontradas en esta revisión integral. Destaca en este cuadro que las referencias están organizadas según: revista en donde fueron publicados, el año de publicación, la base de datos donde fue encontrado, el título, el tipo de estudio, el nivel de evidencia (NE) y los principales resultados de la investigación para responder esta revisión integral.

\section{Cuadro Sinóptico 1}

\begin{tabular}{|c|c|c|c|c|c|c|}
\hline Revista & Año & $\begin{array}{l}\mathrm{Ba} \\
\mathrm{se}\end{array}$ & Título & $\begin{array}{l}\text { Tipo de } \\
\text { Estudio }\end{array}$ & $\begin{array}{l}\mathbf{N} \\
\mathbf{E}\end{array}$ & Principales Resultados \\
\hline $\begin{array}{l}\text { Revista } \\
\text { Ciência } \\
\text { e Saúde } \\
\text { Coletiva } \\
\text { (9) }\end{array}$ & $\begin{array}{l}2 \\
0 \\
0 \\
8\end{array}$ & $\begin{array}{l}\text { Lil } \\
\text { ac } \\
\text { s }\end{array}$ & $\begin{array}{l}\text { Afección } \\
\text { del } \\
\text { tendón } \\
\text { supra- } \\
\text { espinal } \\
\text { y baja } \\
\text { laboral }\end{array}$ & $\begin{array}{l}\text { Cualitati } \\
\text { vo } \\
\text { Descrip } \\
\text { tivo } \\
\text { Investi } \\
\text { gación } \\
\text { de } \\
\text { campo }\end{array}$ & 3 & $\begin{array}{l}\text { El estudio relata los problemas } \\
\text { comunes debido a la sobrecarga } \\
\text { mecánica laboral que afecta al } \\
\text { tendón supra-espinal causando } \\
\text { enfermedades profesionales como } \\
\text { tendinitis y otras. El estudio llama la } \\
\text { atención sobre la necesidad de } \\
\text { investigar la especificidad de las } \\
\text { causas y efectos, relacionado con } \\
\text { determinado tipo de actividad y las } \\
\text { implicaciones en el hombro, } \\
\text { habiendo un elevado número de } \\
\text { bajas debido a la dolencia del } \\
\text { tendón, caracterizándose como } \\
\text { importante problema epidemiológico. }\end{array}$ \\
\hline $\begin{array}{l}\text { Revista } \\
\text { Ciência } \\
\text { e Saúde } \\
\text { Coletiva } \\
(10)\end{array}$ & $\begin{array}{l}2 \\
0 \\
0 \\
9\end{array}$ & $\begin{array}{l}\text { Lil } \\
\text { ac } \\
\text { s }\end{array}$ & $\begin{array}{l}\text { Los } \\
\text { recoge } \\
\text { dores de } \\
\text { residuos } \\
\text { urbanos } \\
\text { en el } \\
\text { Munici } \\
\text { pio de } \\
\text { Doura } \\
\text { dos } \\
\text { (mg) } \\
\text { y su } \\
\text { percep } \\
\text { ción } \\
\text { sobre } \\
\text { los } \\
\text { riesgos } \\
\text { biológi } \\
\text { cos en } \\
\text { su } \\
\text { proceso } \\
\text { de } \\
\text { trabajo }\end{array}$ & $\begin{array}{l}\text { Cualitati } \\
\text { va } \\
\text { Descrip } \\
\text { tiva } \\
\text { Investi } \\
\text { gación } \\
\text { de } \\
\text { campo }\end{array}$ & 3 & $\begin{array}{l}\text { El estudio con los recogedores de } \\
\text { residuos urbanos observó que } \\
\text { durante el proceso de trabajo están } \\
\text { expuestos a riesgos físicos, } \\
\text { químicos, mecánicos, ergonómicos, } \\
\text { siendo el principal el biológico. Este } \\
\text { es causado por los materiales } \\
\text { perfuro-cortantes como: agujas y } \\
\text { vidrios desechados incorrectamente } \\
\text { en la basura domiciliaria. Estos } \\
\text { riesgos causan enfermedades como: } \\
\text { infecciones agudas o crónicas, } \\
\text { parasitosis, fracturas, micosis. Se } \\
\text { identificó la urgente necesidad de } \\
\text { proporcionar informaciones a los } \\
\text { recogedores de residuos y a la } \\
\text { población. Los trabajadores } \\
\text { necesitan recibir instrucciones sobre } \\
\text { cómo suavizar o evitar riesgos } \\
\text { laborales. La población precisa ser } \\
\text { orientada sobre cómo almacenar y } \\
\text { desechar los residuos sólidos } \\
\text { correctamente para preservar el }\end{array}$ \\
\hline
\end{tabular}




\begin{tabular}{|c|c|c|c|c|c|c|}
\hline & & & & & & $\begin{array}{l}\text { medio ambiente, su propia salud y la } \\
\text { salud de los trabajadores de la } \\
\text { recogida de residuos. }\end{array}$ \\
\hline $\begin{array}{l}\text { Revista } \\
\text { de } \\
\text { Enferm } \\
\text { agem } \\
\text { Cogitar } \\
\text { e }^{(11)}\end{array}$ & $\begin{array}{l}2 \\
0 \\
0 \\
9\end{array}$ & $\begin{array}{l}\text { Lil } \\
\text { ac } \\
\text { s }\end{array}$ & $\begin{array}{l}\text { Exposi } \\
\text { ción } \\
\text { laboral } \\
\text { con } \\
\text { material } \\
\text { potenci } \\
\text { almente } \\
\text { contami } \\
\text { nado } \\
\text { entre } \\
\text { profesio } \\
\text { nales } \\
\text { del área } \\
\text { de } \\
\text { apoyo }\end{array}$ & $\begin{array}{l}\text { Cualitati } \\
\text { vo } \\
\text { Descrip } \\
\text { tivo } \\
\text { Investig } \\
\text { ación } \\
\text { de } \\
\text { campo }\end{array}$ & 3 & $\begin{array}{l}\text { El estudio levantó la frecuencia de } \\
\text { accidentes laborales, incluyendo } \\
\text { materiales biológicos potencialmente } \\
\text { contaminados. Los resultados } \\
\text { señalaron que de } 2004 \text { a 2009, } \\
12,4 \% \text { eran profesionales del servicio } \\
\text { de limpieza, el } 3^{\circ} \text { grupo más } \\
\text { registrado, consecuencia de su } \\
\text { proceso de trabajo de recogida de } \\
\text { residuos hospitalarios, y en } \\
\text { actividades administrativas, cuando } \\
\text { tales materiales son desechados en } \\
\text { lugar inadecuado. Las exposiciones } \\
\text { percutáneas ocurrieron por } \\
\text { encapuchado de agujas. Para } \\
\text { fortalecer prácticas integradas } \\
\text { capaces de proporcionar seguridad y } \\
\text { ambiente saludable, tres pilares de la } \\
\text { asistencia deben ser fortalecidos: el } \\
\text { sistema de información para ayudar } \\
\text { la política institucional, la formación } \\
\text { continua de los profesionales que } \\
\text { generan residuo perfuro-cortante } \\
\text { ocasionando accidentes en la limpieza, la } \\
\text { profesionales de la } \\
\text { inserción de tecnología segura con } \\
\text { dispositivo de seguridad. }\end{array}$ \\
\hline $\begin{array}{l}\text { Revista } \\
\text { de } \\
\text { Salud } \\
\text { Pública } \\
\text { (12) }\end{array}$ & $\begin{array}{l}2 \\
0 \\
0 \\
9\end{array}$ & $\begin{array}{l}\text { Lil } \\
\text { ac } \\
\text { s }\end{array}$ & $\begin{array}{l}\text { Riesgos } \\
\text { labora } \\
\text { les en el } \\
\text { contexto } \\
\text { hospital } \\
\text { lario: } \\
\text { Desafío } \\
\text { para } \\
\text { Salud } \\
\text { del } \\
\text { trabaja } \\
\text { dor }\end{array}$ & $\begin{array}{l}\text { Cualitati } \\
\text { vo } \\
\text { Descrip } \\
\text { tivo } \\
\text { Investi } \\
\text { gación } \\
\text { de } \\
\text { campo }\end{array}$ & 3 & $\begin{array}{l}\text { El estudio objetivó analizar las } \\
\text { representaciones sociales de los } \\
\text { trabajadores de salud en general } \\
\text { (englobando los trabajadores del } \\
\text { servicio de limpieza) acerca de los } \\
\text { riesgos laborales. Los resultados } \\
\text { revelaron el descontento con las } \\
\text { condiciones insalubres e inseguras } \\
\text { de trabajo en el contexto hospitalario. }\end{array}$ \\
\hline $\begin{array}{l}\text { Revista } \\
\text { da } \\
\text { Escola } \\
\text { de } \\
\text { Enferm } \\
\text { agem } \\
\text { da USP } \\
\text { (13) }\end{array}$ & $\begin{array}{l}2 \\
0 \\
0 \\
9\end{array}$ & $\begin{array}{l}\text { Lil } \\
\text { ac } \\
\text { s/ } \\
\text { bd } \\
\text { enf }\end{array}$ & $\begin{array}{l}\text { Calidad } \\
\text { de } \\
\text { vida y } \\
\text { sínto } \\
\text { mas } \\
\text { osteo } \\
\text { muscula } \\
\text { res } \\
\text { en }\end{array}$ & $\begin{array}{l}\text { Cualitati } \\
\text { vo } \\
\text { Descrip } \\
\text { tivo } \\
\text { Investi } \\
\text { gación } \\
\text { de }\end{array}$ & 3 & $\begin{array}{l}\text { El estudio tuvo como objetivo } \\
\text { identificar aspectos de la calidad de } \\
\text { vida y los síntomas osteomusculares } \\
\text { en trabaljadores del servicio de } \\
\text { limpieza hospitalaria. El resultado } \\
\text { demostró que la mitad de los } \\
\text { trabajadores indicó los hombros } \\
\text { como segmento más afectado por los } \\
\text { síintomas osteomusculares, y para }\end{array}$ \\
\hline
\end{tabular}




\begin{tabular}{|c|c|c|c|c|c|c|}
\hline & & & $\begin{array}{l}\text { trabaja } \\
\text { dores } \\
\text { de } \\
\text { higiene } \\
\text { y } \\
\text { limpieza } \\
\text { hospital } \\
\text { aria }\end{array}$ & campo & & $\begin{array}{l}\text { muchos impidiéndoles la realización } \\
\text { de las tareas laborales. Observó } \\
\text { diferencias significativas para los } \\
\text { trabajadores de limpieza con los de } \\
\text { enfermería. La enfermería solo } \\
\text { sobrepasa en las regiones lumbar y } \\
\text { dorsal. }\end{array}$ \\
\hline $\begin{array}{l}\text { Revista } \\
\text { Ciência } \\
\text { e Saúde } \\
\text { Coletiva } \\
(14)\end{array}$ & $\begin{array}{l}2 \\
0 \\
1 \\
0\end{array}$ & $\begin{array}{l}\text { Lil } \\
\text { ac } \\
\text { s }\end{array}$ & $\begin{array}{l}\text { Virus de } \\
\text { la } \\
\text { hepatitis } \\
\text { B: } \\
\text { evalua } \\
\text { ción y } \\
\text { Res } \\
\text { puesta } \\
\text { serológi } \\
\text { ca a la } \\
\text { vacuna } \\
\text { en } \\
\text { funciona } \\
\text { rios de } \\
\text { limpieza } \\
\text { en el } \\
\text { hospital } \\
\text { escuela }\end{array}$ & $\begin{array}{l}\text { Cualitati } \\
\text { vo } \\
\text { Descrip } \\
\text { tivo } \\
\text { Investi } \\
\text { gación } \\
\text { de } \\
\text { campo }\end{array}$ & 3 & 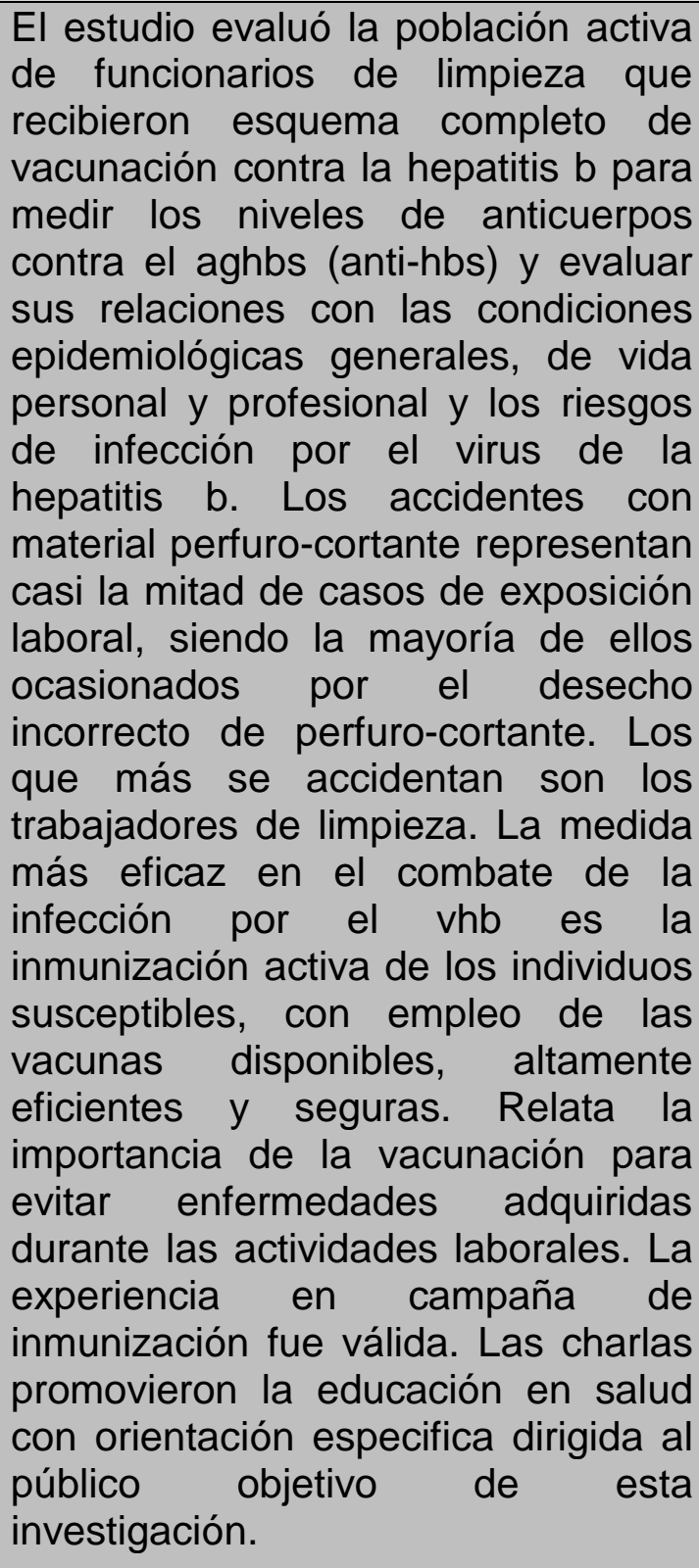 \\
\hline $\begin{array}{l}\text { Revista } \\
\text { Ciência } \\
\text { e Saúde } \\
\text { Coletiva } \\
\text { (15) }\end{array}$ & $\begin{array}{l}2 \\
0 \\
1 \\
1\end{array}$ & $\begin{array}{l}\text { Lil } \\
\text { ac } \\
\text { s }\end{array}$ & $\begin{array}{l}\text { Enferme } \\
\text { ría y } \\
\text { Atención } \\
\text { a la } \\
\text { salud } \\
\text { del } \\
\text { Trabaja } \\
\text { dor: la } \\
\text { expe } \\
\text { riencia }\end{array}$ & $\begin{array}{l}\text { Cualitati } \\
\text { vo } \\
\text { Descrip } \\
\text { tivo } \\
\text { Investi } \\
\text { gación } \\
\text { de } \\
\text { campo }\end{array}$ & 3 & $\begin{array}{l}\text { El estudio relata la importancia de la } \\
\text { vacunación para evitar } \\
\text { enfermedades que puedan llevar a la } \\
\text { muerte de los trabajadores causados } \\
\text { por agentes biológicos adquiridos } \\
\text { durante la realización de las } \\
\text { actividades laborales. Como } \\
\text { resultado de este trabajo se aplicaron } \\
12.904 \text { dosiss de vacunas variadas } \\
\text { en una población de trabajadores de }\end{array}$ \\
\hline
\end{tabular}




\begin{tabular}{|c|c|c|c|c|c|c|}
\hline & & & $\begin{array}{l}\text { de la } \\
\text { acción } \\
\text { de } \\
\text { inmuni } \\
\text { zación } \\
\text { en la } \\
\text { Fiocruz/ } \\
\text { Manguin } \\
\text { hos }\end{array}$ & & & $\begin{array}{l}\text { actividad y grupos de edad } \\
\text { diversificados. La experiencia en } \\
\text { campaña de inmunización fue válida. } \\
\text { Las charlas promovieron la } \\
\text { educación en salud con orientación } \\
\text { específica dirigida al público objetivo } \\
\text { de esta investigación. }\end{array}$ \\
\hline $\begin{array}{l}\text { Revista } \\
\text { Paulista } \\
\text { de } \\
\text { Enferm } \\
\text { agem } \\
(16)\end{array}$ & $\begin{array}{l}0 \\
1 \\
3\end{array}$ & $\begin{array}{l}\text { Lil } \\
\text { ac } \\
\text { s }\end{array}$ & $\begin{array}{l}\text { Significa } \\
\text { do de la } \\
\text { carga de } \\
\text { trabajo } \\
\text { bajo la } \\
\text { óptica } \\
\text { de } \\
\text { trabaja } \\
\text { dores } \\
\text { de } \\
\text { limpieza }\end{array}$ & $\begin{array}{l}\text { Cualitati } \\
\text { vo } \\
\text { Descrip } \\
\text { tivo } \\
\text { Investi } \\
\text { gación } \\
\text { de } \\
\text { campo }\end{array}$ & 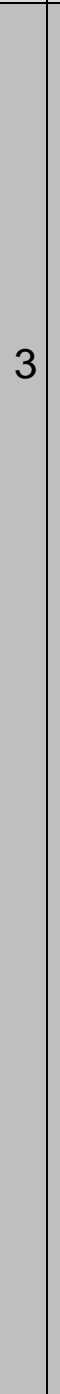 & $\begin{array}{l}\text { El objetivo del estudio fue analizar el } \\
\text { significado de la carga de trabajo } \\
\text { para trabajadores de limpieza de una } \\
\text { unidad de urgencia e identificar } \\
\text { estrategias para protección de esta } \\
\text { carga. Se observó que las cargas de } \\
\text { trabajo significativas para los } \\
\text { trabajadores son las de naturaleza } \\
\text { fisiológica, principalmente } \\
\text { relacionadas con dolor en la espalda, } \\
\text { de naturaleza psíquica relacionada } \\
\text { con la convivencia en ambiente } \\
\text { envuelto en sufrimiento y situaciones } \\
\text { inesperadas, de naturaleza } \\
\text { psicológica debido a la no } \\
\text { valorización del trabajo por los otros } \\
\text { profesionales trabajadores en el } \\
\text { ambiente laboral, la cuestión de } \\
\text { relación interpersonal, el trabajo en } \\
\text { equipo y también las cargas de } \\
\text { contaminación biológica. } \\
\text { resultados indicaron que la estrategia } \\
\text { colectiva precisa ser adoptada para } \\
\text { ampliar las informaciones que los } \\
\text { trabajadores de limpieza tienen en } \\
\text { relación a la carga de trabajo, es } \\
\text { necesario valorar el trabajo de estas } \\
\text { personas posibilitándoles mayor } \\
\text { participación en el trabajo en equipo. }\end{array}$ \\
\hline
\end{tabular}

Según el cuadro, clasificamos los artículos presentados según los asuntos tratados por cada autor, surgiendo tres ejes temáticos para discusión: (1) Enfermedades laborales, (2) Factores causales de las enfermedades laborales, (3) Medidas educativas para minimizar las enfermedades laborales. El artículo 1 habla sobre enfermedades laborales, factores causales y medidas educativas, los artículos 2, 5, 6 abordan las enfermedades laborales. Los artículos 4 y 8 tratan sobre factores causales, el artículo 3 sobre factores causales y medidas educativas. Por último, los artículos $6,7,8$ se centran en las medidas educativas para minimizar las enfermedades laborales. 


\section{DISCUSIÓN}

\section{Enfermedades laborales}

Las enfermedades laborales relatadas en los artículos de esta categoría fueron: problemas osteomusculares LER/ DORT (tendinitis, burcitis, trastornos del manguito rotador, lumbalgias); dermatitis, rinitis, hepatitis $\mathrm{B}$ y $\mathrm{C}$, parasitosis, trastornos alimentarios y del sueño, depresión, neurosis, reacciones alérgicas y tóxicas, HIV, infecciones agudas o crónicas y micosis.

Para iniciar la discusión de esta categoría, como las enfermedades osteomusculares fueron las que más aparecieron, se trazó el concepto de que estas se caracterizan por síntomas dolorosos que afectan a tendones, músculos, nervios, ligamentos y otras estructuras responsables de los movimientos de los miembros superiores, espalda, zona del cuello, hombros y miembros inferiores ${ }^{(17)}$.

Los trastornos musculoesqueléticos acarrean un grave problema de salud pública y uno de los más graves en el campo de la salud del trabajador, llevándolo a diferentes grados de incapacidad funcional, generando un aumento de absentismo y de abandonos temporales o permanentes del trabajador y produciendo costo importante en tratamiento e indemnizaciones ${ }^{(17)} \quad$ Lumbalgia - es una enfermedad que compromete ligamentos, músculos y/o lesiones de los discos intervertebrales, caracterizada por la presencia de cuadro doloroso en intensidad que compromete la realización de las actividades laborales ${ }^{(17)}$.

\section{Factores causales de las enfermedades laborales}

A través del análisis de los artículos fue posible identificar y delimitar los temas relacionados con los riesgos y factores causales de las enfermedades a que están expuestos los trabajadores de limpieza en ambiente hospitalario. Los riesgos: físicos (ruido, calor, humedad y frío); químicos: (contacto con productos de limpieza, desecho de quimioterápicos); mecánicos (caidas); ergonómicos (esfuerzos repetitivos, postura inadecuada, equipamientos inadecuados); biológicos: (contacto con secreciones y fluídos corpóreos durante la limpieza, contaminación con material perfuro-cortante); Ergonómico cognitivo: (desvalorización social del trabajo, pérdirda de la motivación). Factores causales: número insuficiente de trabajadores, sobrecarga de trabajo, exposición ocupacional, condiciones físicas impropias, falta de capacitación profesional, negligencia o mal uso de EPIs.

De modo a iniciar la discusión de esta categoría se destaca que la salud laboral o salud del trabajador se refiere a la promoción y preservación de la integridad física del trabajador durante el ejercicio de su función, destacando por medio del abordaje de prevención, cribado y diagnóstico precoz de los problemas de salud relacionados con el trabajo, además de la constatación de la existencia de casos de enfermedades profesionales o daños irreversibles para la salud del trabajador ${ }^{(18)}$.

La identificación de los factores de riesgo tiene como objetivos principales reconocer y evaluar los riesgos indicando maneras de gerenciamiento, buscando medir, y si posible, disminuir la incidencia de accidentes de trabajo a los que están expuestos los trabajadores de limpieza durante el desarrollo de sus actividades laborales. 
Dentro de ese panorama destacan los factores que llevan al trabajador a los riesgos laborales que se originan de actividades laborales insalubres pudiendo provocar efectos adversos a la salud del profesional ${ }^{(19)}$.

De entre los factores que llevan a la ocurrencia de los riesgos laborales, los principales son:

(1) Número insuficiente de funcionarios - El déficit de profesionales acarrea una sobrecarga de trabajo, porque una vez que hay un número mayor de sectores para cada funcionario, perjudica la interacción con sus funciones y con el ambiente de trabajo, en la medida en que este ambiente contiene demanda excesiva ${ }^{(20)}$.

(2) Sobrecarga de trabajo - El servicio de limpieza es un trabajo desgastante, en especial en las instituciones públicas. La sobrecarga de trabajo puede interferir en la calidad de vida del trabajador ${ }^{(21)}$.

(3) Falta de capacitación profesional - Muchas variables contribuyen a la ocurrencia de los riesgos laborales, la falta de capacitación profesional es una de ellas, evidenciando la necesidad de creación de estrategias dirigidas a estos trabajadores, para la prevención de accidentes durante las actividades laborales. Los hospitales podrían establecer una política permanente de educación y capacitación de los trabajadores ${ }^{(22)}$.

(4) Exposición laboral - Ante los riesgos biológicos, las infecciones más preocupantes son aquellas causadas por los virus del AIDS (HIV), de las hepatitis ( $\mathrm{B}$ y $\mathrm{C})$, siendo la principal vía de transmisión laboral por medio de la exposición a sangre, vía accidente perfuro-cortante ${ }^{(23)}$.

(5) Condiciones físicas impropias - Las principales quejas presentadas por este grupo de trabajadores son: reacciones alérgicas, enfermedades infectocontagiosas, fatiga, lumbalgias y los problemas osteomusculares causados por esfuerzos repetitivos, postura inadecuada ${ }^{(24)}$.

(6) Indisposición por mal uso de los EPIs - En el ambiente hospitalario el trabajo es arriesgado e insalubre, por eso, muchas veces los trabajadores realizan sus tareas sin la protección adecuada, o haciendo uso de los EPIs de modo inadecuado, llevando à condiciones laborales impropias derivadas de la falta de recursos y materiales de los hospitales, así como la falta de concienciación de los trabajadores sobre el uso de EPI ${ }^{(25)}$.

\section{Medidas educativas para minimizar las enfermedades laborales.}

Las medidas de prevención encontradas en los artículos:

- Orientación a los profesionales de limpieza a través de formación hospitalaria, enseñando medidas de prevención y uso correcto del EPI.

- Formación continua a los profesionales que generan residuos, principalmente los perfuro-cortantes.

- Orientación sobre la importancia de la inmunización contra hepatitis B y C.

- Sistema de información para ayudar la política institucional.

- Inserción de tecnología segura con dispositivo de seguridad.

- Mantener postura correcta en las ejecuciones de los procedimientos.

- Realizar actividad física (gimnástica laboral).

- Educación continuada y permanente para el trabajador que actúa en ambiente hospitalario. 
Al discutir esta categoría es importante implementar medidas para prevenir, evitar o reducir los daños que la exposición laboral provoca en los profesionales en enfoque, creando programas de formación y desarrollo personal, promoviendo educación en servicio, introduciendo charlas y formación en el ambiente hospitalario. La adhesión a estas medidas requiere cambios en las conductas y en el comportamiento del profesional, pues son los obstáculos a ser vencidos referentes a la prevención de los riesgos laborales ${ }^{(26)}$.

Así, para evitar la enfermedad del trabajador en ambiente hospitalario, de acuerdo con la Norma reglamentadora 32 (NR-32) es obligación del empleador proprcionar el número necesario de EPI a los trabajadores, garantizando también calidad y la orientación para el correcto uso. En esta situación, cabe a los enfermeros de los servicios de limpieza saber las particularidades de la función ejecutada, con la finalidad de implementar medidas de prevención, promoviendo la salud de los profesionales de limpieza ${ }^{(27)}$.

Las medidas educativas evidenciadas en esta revisión tienen como norte la formación y se pautan así en la educación continuada. Se destaca que la educación es el medio más eficaz para modificar y crear hábitos de rutina en el ambiente de trabajo. La educación continuada es definida como un conjunto de actividades educativas para la actualización del individuo, donde se facilita el desarrollo del funcionario así como su participación eficaz en el día a día de la institución ${ }^{(28)}$. Por eso, la educación permanente trabaja de forma multiprofesional, busca una práctica institucionalizada, tiene por objetivo la transformación de prácticas técnicas y sociales, la periodicidad es contínua, se fundamenta en la pedagogía centrada en la resolución de problemas, donde el resultado es el cambio institucional, la apropiación activa del saber científico fortalece el equipo de trabajo ${ }^{(29)}$. Educación permanente tiene por objetivo trabajar con los equipos y no con los trabajadores corporativamente organizados, o sea, presentan enfoque multiprofesional e interdisciplinar ${ }^{(30)}$.

En este contexto, siendo los trabajadores de limpieza trabajadores que no forman parte de los trabajadores de salud, muchas de las veces participan de procesos educativos aislados del contexto y separados de los profesionales de salud, lo que puede ser un indicativo de fracaso.

Destaca por útlimo, que todo proceso educativo no tiene un fin en sí mismo. Es un proceso inacabado, siendo necesario retroalimentarlo continuamente por la dinámica del sector de salud, y la Educación Permanente puede ser una herramienta para esa construcción ${ }^{(31)}$.

\section{CONCLUSIÓN}

Ante esta revisión integral se percibe la importancia de la prevención y del conocimiento sobre los factores de riesgo para el profesional que desarrolla sus actividades en el ambiente hospitalario, y que decisiones referentes a los cuidados con el uso adecuado de los equipos evitarán problemas de salud para estos trabajadores los cuales están expuestos diariamente. Se observa que estas no son cumplidas, no sólo por falta de conocimiento, sino por comodidad e inexistencia de compromiso con su propia seguridad. 
El profesional que trabaja en el ambiente hospitalario está expuesto a diversos riesgos laborales, tales como accidentes de trabajo, desgaste mental y emocional, sobrecarga de trabajo, condiciones físicas inadecuadas, y tales problemas pueden afectar al desempeño del trabajador poniendo en riesgo a todas las personas involucradas en el proceso, y consecuentemente alterando la dinámica del servicio, así como comprometiendo la calidad del servicio prestado.

En fin, se entiende cómo es de esencial e importante que los profesionales busquen formas para modificar sus conductas y actitudes y que estén preparados para enfrentar cambios con la intención de suavizar problemas a los que están expuestos diariamente, a través de la adquisición de conocimientos de sus derechos y deberes, para que consigan trabajar con seguridad y menos daños para su salud.

Se notó que las actividades educativas con foco en la formación son las más realizadas y ha de haber un cuestionamento si es que no cambia el panorama, pues está comprobado que educación con foco en formación no cambia las actitudes, comportamiento y el proceso de trabajo, pero sí la educación permanente. Así, se sugiere la implementtación de educación permanente en los lugares de trabajo en que está esta categoría profesional de modo que el proceso educativo sea significativo y las enfermedades laborales entre ellos disminuyan.

\section{REFERENCIAS}

1) Mendes R. Patologia do trabalho. Rio de Janeiro: Atheneu, 1995.

2) Dias EC. Evolução e aspectos atuais da saúde do trabalhador no Brasil. Bol. Of. Sanit. Panam. 1993; 115(3):202-14.

3) Arruda ECSR, Ribeiro MC, Brasileiro ME. Identificação dos riscos institucionais em profissionais de enfermagem. Revista Eletrônica de Enfermagem e Nutrição [periódico na internet]. 2010 jan-jul [acesso em 2013 dez 09]; 1(1):1-16. Disponível em: http://www.ceen.com.br/revista eletronica

4) Franco AR. Estudo preliminar das repercussões do processo de trabalho sobre a saúde dos trabalhadores de um hospital geral. Ribeirão Preto. [Tese de Doutorado]; Universidade de São Paulo/USP; 1981.

5) Pompeu DA, Rossi LA, Galvão CM. Revisão integrativa: etapa inicial do processo de validação do diagnóstico de enfermagem. Acta Paul Enferm. 2009; 22(4):434-8.

6) Nobre MR, Bernardo WM, Jatene FB. Evidence based clinical practice. Part 1 well structured clinical questions. Rev Assoc Med Bras. 2003; 49(4): 445-9.

7) Cruz DALM; Pimenta CAM. Prática baseada em evidências, aplicada ao raciocínio diagnóstico. Rev Latino-Am Enfermagem. 2005; 13 (3):415-22.

8) Magarey JM. Elements of a systematic review. Int J Nurs Pract. 2001;7(6):37682.

9) Almeida JS, Filho GC, Pastre CM, Lamari NM, Pastre EC. Afecções do tendão supra-espinal e afastamento laboral. Ciênc Saúde Coletiva [periódico na internet]. 2008 [acesso em 2013 dez 9];13:1-6. Disponível em: http://www.scielo.br/scielo.php?script=sci arttext\&pid=S141381232008000200027\&lng=en\&nrm=iso

10) Lazzari MA, Reis CB. Os coletores de lixo urbano no município de Dourados (MG) e sua percepção sobre o risco biológico em seu processo de trabalho. Ciênc Saúde Coletiva [periódico na internet]. 2011[acesso em 2013 dez 9];16(8):3437-42.

Disponível

em: 
http://www.scielo.br/scielo.php?script=sci arttext\&pid=S1413-

$81232011000900011 \& \operatorname{lng}=$ en.

11) Morais NO, Paniago AMM, Negri AC, Oliveira OA, Cunha RV, Oliveira SMVL. Exposição ocupacional com material potencialmente contaminado entre profissionais da área de apoio. Cogitare enferm. 2009;14(4):1-7.

12) Oliveira JDS, Alves MSCF, Miranda FAN. Riscos ocupacionais no contexto hospitalar: desafio para a saúde do trabalhador. Rev salud pública. 2009; 11(6):909-17.

13) Martarello NA, Benetti MCC. Qualidade de vida e sintomas e sintomas osteomusculares em trabalhadores de higiene e limpeza hospitalar. Rev esc enferm USP. [periódico na Internet]. 2009[acesso em 2013 dez 9];43(2):422428.

Disponível

em:

http://www.scielo.br/scielo.php?script=sci arttext\&pid=S008062342009000200023\&lng $=$ en.

14) Osti $C$, Machado JM. Hepatite B: avaliação da resposta sorológica á vacina em funcionários de limpeza hospital-escola. Ciênc saúde coletiva [periódico na internet]. 2010 [acesso em 2013 dez 9];15(Suppl 1):1343-1348. Disponível em: http://www.scielo.br/scielo.php?script=sci arttext\&pid=S1413$81232010000700043 \&$ Ing $=$ en.

15) Santos $P R$, Noronha $\mathrm{NH}$, Mattos $A O$, Silva $D$. Enfermagem e atenção á saúde do trabalhador: a experiência da ação de imunização na Fiocruz/Manguinhos. Ciênc Saúde Coletiva [periódico na internet]. 2011 [acesso em 2013 dez 9];16(2):553-65.

Disponível

em:

http://www.scielo.br/scielo.php?script=sci arttext\&pid=S1413$81232011000200019 \& \operatorname{lng}=$ en\&nrm=iso

16) Martins JT, Ribeiro RP, Bobroff MCC, Marziale MHP, Robazzi CC, Mendes A C. Significado de carga no trabalho sob a ótica de operacionais de limpeza. Acta paul enferm. 2013; 26(1): 63-70.

17) Souza AN, Silva AP, Oliveira TL, Brasileiro ME. A atuação do enfermeiro do trabalho na prevenção dos riscos ergonômicos no ambiente hospitalar. Revista Eletrônica de Enfermagem do Centro de Estudos de Enfermagem e Nutrição. [periódico na internet] 2011; 2(2): 1-11.Disponível em: HTTP://www.ceen.com.br/revistaeletronica

18) Leitão IMA, Fernandes AL, Ramos IC. Saúde ocupacional: analisando os riscos relacionados à equipe de enfermagem numa unidade de terapia intensiva. Cienc Cuid Saude. 2008; 7(4):476-84.

19) Castro AB, Souza ITC, Santos AA. Atribuições do enfermeiro do trabalho na prevenção de riscos ocupacionais. J Health Sci Inst.2010; 28(1):5-7.

20) Pereira CA, Miranda LCS, Passos JP. O estresse ocupacional da equipe de enfermagem em setor fechado. Rev de Pesq cuidado é fundamental Online [periódico na internet]. 2009 [acesso em 2013 dez 9]; 1(2):196-202. Disponível em:

http://www.seer.unirio.br/index.php/cuidado\%20fundamental/article/viewArticle/3 $\underline{46}$

21) Monteiro CM, Benatti MCC, Rodrigues RCM. Acidente do trabalho e qualidade de vida relacionado à saúde: um estudo em três hospitais. Rev Latino-Am. Enfermagem. 2009; 17(1):101-7.

22) Barbosa MA, Figueiredo VSL, Paes MSL. Acidente de trabalho envolvendo Enfermagem profissionais de enfermagem no ambiente hospitalar: um levantamento do banco de dados. Revista de Enfermagem Integrada - Ipatinga, Unileste (MG). 2009; 2(1):176-187.

23) Neves HCC, Souza ACS, Medeiros M, Munari DB, Ribeiro LCM, Tipple AFV. 
Segurança dos trabalhadores de enfermagem e fatores determinantes para adesão aos equipamentos de proteção individual. Rev Latino-Am. Enfermagem. 2011; 19(2): 354-361.

24)Miranda EJP, Stancato $K$. Riscos à saúde de equipe de enfermagem em unidade de terapia intensiva: proposta de abordagem integral da saúde. Rev bras ter intensive. 2008; 20(1):68-76.

25)Giomo DB, Freitas, FCT, Alves, LA, Robazzi MLCC. Acidentes ocupacionais e absenteísmo entre os trabalhadores de enfermagem hospitalar. Rev enferm UERJ. 2009; 17(1):24-9.

26) Veras NK, Alexandria FED Normas em controle de infecções hospitalares, 2008. Comissão de Controle de Infecção Hospitalar - CCIH Terezina. Fundação Municipal de Saúde [Acesso em 2013 dez 9]. Disponível em: http://pt.scribd.com/doc/7154947/Manual-de-Rotinas-Em-CClH .

27) Brasil. Lei orgânica da saúde $n^{\circ}$ 8080/90, de 19 de setembro de 1990. Brasília: Ministério da Saúde. Disponível em: http://www.planalto.gov.br/ccivil 03/leis//8080.htm

28) Silva MC, Fassa AC, Valle NGJ. Dor lombar crônica em uma população adulta no sul do Brasil: prevalência e fatores associados. Cad Saúde Pública. 2004; 20:377-85.

29)Ceccim RB. Educação Permanente em Saúde: desafio ambicioso e necessário. Interface Comum Saúde Educ. 2005;9(16):161-8.

30) Cunha AC, Mauro MYC. Educação Continuada e Norma Regulamentadora 32: utopia ou realidade na enfermagem? Rev Bras Saúde ocup. 2010; 35(122):30513.

31) Merty EE, Feuerwerker LCM, Ceccim RB. Educación permanente en salud: una estratégia para intervenir en la micropolítica del trabajo en salud. Sadud Colect. 2006; 2(2):147-60.

Recibido: 24 de enero 2015; Aceptado: 26 de mayo 2015

ISSN 1695-6141

( ) COPYRIGHT Servicio de Publicaciones - Universidad de Murcia 